\title{
Screening of phytochemicals from Golden apple of discord, Cydonia oblonga against the pTen and HBx using in silico-based tools.
}

\author{
Elhan Khan \\ Integral University \\ Iffat Zareen Ahmad ( $\square$ iffat@iul.ac.in ) \\ Integral University https://orcid.org/0000-0003-2583-1794
}

\section{Research Article}

Keywords: Cydonia oblonga, quince, bioactive compounds, anti-cancer, hepatocarcinoma, molecular docking, molecular dynamics

Posted Date: October 12th, 2021

DOI: https://doi.org/10.21203/rs.3.rs-960905/v1

License: (c) (1) This work is licensed under a Creative Commons Attribution 4.0 International License. Read Full License 


\section{Abstract \\ Background}

Phytochemicals derived from Cydonia oblonga have been investigated for their anti-oxidant and anti-cancer activities in many cancer cells lines. The reported bioactive compounds are evaluated in-silico to develop a novel antagonist against pTEN and HBx to target hepatocellular carcinoma. Lower expression of pTEN or higher expression of HBx represents the progression of hepatocellular carcinoma (HCC).

\section{Objective}

This research is intended to identify the best candidate which interacts with our target proteins (pTEN and HBx) from the quince seeds by using computational methodologies.

\section{Materials and Methods}

The ternary structures of protein and phytochemicals reported in quince like derivatives of caffeoylquinic acid, kaempferol and quercetin, Chrysoeriol, Catechin and other compounds are retrieved from the online databanks. Druglikness analysis and ADMET profiling was done, followed by docking analysis. Lastly, molecular dynamics study was done to determine the complexes stability.

\section{Results}

Docking study revealed that CQA derivatives have the significant inhibitory potential of 3CQA and 5CQA with binding affinity of -7.53 and -7.49 against PTEN and -5.94 and -6.01 against $\mathrm{HBx}$ in comparison to the standard drug doxorubicin. The average RMSD and RMSF value for protein-ligand complexes were found quite stable comparative to the standard, while parameters like gyration and SASA supports the complexes having the significant binding and stability especially against pTEN.

\section{Conclusion}

The results obtained from the evaluation depict 3CQA and 5CQA shows best stability especially with the p10 protein target. Hence, these compounds have to be considered for detailed experimental studies to understand its biological function against HCC.

\section{Introduction}

Liver cancer or also known as Hepatocellular carcinoma (HCC), a tumor originates from hepatocytes is the disease which causes the second highest mortality worldwide according to the GLOBOCON report 2018. The major etiology agents accountable for HCC are consumption of aflatoxin B1 in foods, DDT (Dichloro diphenyl trichloroethane) and organic chlorides in water and alcohol, chronic liver injury, alcoholic and biliary cirrhosis, hemochromatosis and due to virus infections like HBV and HCV (hepatitis B and $C$ virus) [1]. Many studies have been reported that HCV infection was found in $40 \%-80 \%$ of HCC cases [2], that is strenuously correlated to liver insulin resistance which results in the causes of fibrosis and steatosis [3]. Several potential tumor suppressing genes (TSG) and oncogenes are used for the early-stage identification of HCC as a biomarker that is active in the progression of HCC.

Along with Arf, p53 and Ink4a, the tumor suppressor gene pTEN which is discovered in 1997 is one of the most influential cancermutated genes. It is located specifically from $87,863,438$ base pare (b.p) to b.p $87,971,930$ of chromosome 10 at position 23.3 and 10q23 locus. The crucial role of p10 is dephosphorylation of downstream phosphatidylinositol 3,4,5trisphosphate in normal hepatocytes, thus down-regulating signaling pathways like PI3K/Akt/mTOR $[4,5]$. pTEN, however, has negative regulative impact on downstream pathway in case of its deletion or mutation resulting a decline in the normal regulative mechanism of cell 
proliferation or metastasis, thereby causing the prevalence or malignant transformation of tumors. Presently, the abnormal behavior of pTEN is related to the incident and spread of various malignant tumors like endometrial, glioma, liver and prostate cancer [6]. Akt pathway suppression mediated by leads to increase in longevity, insulin signals down-regulation and resulting in tumor suppression [7]. The gene pTEN conjointly seems to be essential for in-vivo study for embryonic development in mouse [8]. Early growth response protein-1, Ras, ROS and NF- KB are some of the pTEN regulators [9]. In a data collected on transgenic mice, the core gene of $\mathrm{HCV}$ is believed to have a crucial role in HCC progression. by down-regulating the expression of retinoblastoma protein $(\mathrm{Rb})$, and altering its tumor suppressive role [10]. The down-regulation of pTEN expression regulated by the core protein of HCV was reported in a research carried out by Zhang et al. (2014), which leads to the activation of downstream Akt gene at transcriptional level. In the in-vitro study, the HepG2 cells that are expressing the core protein of HCV shows significant enhanced proliferation and viability and cells had concentrated in G2/M cell cycle phase [11]. HBx mediated suppression of pTEN expression has also been reported to be involved in the HCC progression [12]. Additional studies have shown over-expression of Matrix Mettalo Protein-9 (MMP-9) as a result of Activator Protein-1 and NF- KB up-regulation and that are controlled through the ERK1/2 and PI3K pathway, leading to increased cell invasion in HBx transfected HCC [13]. pTEN role in HBx induced IGF-2 signaling via PKC or MAPK signaling was discovered to have a low level of IGF-2 at increased level of pTEN expression due to increased transcription factor Sp-1 phosphorylation, thereby limiting tumor progression [14].

The active use of the computational approach to drug development has been documented in several studies in recent years [15]. Computational study of the bioactive compounds of Graviola has been carried out for its anticancer activities, the study helped in narrowing down the number of compounds of interest and thus in reducing the cost of drug discovery [16] and many such studies have been done to screen the natural compounds for the particular target(s) or diseases [17] using in-silico approach. Cydonia oblonga commonly known as Quince has been reported for its broad spectrum of therapeutically values. They are used from centuries as a traditional medicine for constipation, diarrhea, gum problems, respiratory tract disorders, canker sores, asthma, bronchitis, sore throat, cough and even rhinitis. Many studies have been reported for their anti-oxidant, antiseptic, anti-

inflammatory, hepato-protective, and anticancer activities owing to the presence of therapeutically important bioactive compounds [18].

Therefore, this study attempts to index the reported naturally-derived bioactive compounds from the quince seeds for their anticancer activities especially those involve in traditional medicine systems are "drug-like" using the in-silico software's and AutoDock to specify the ADMET (Absorption, Distribution, Metabolism, Excretions and Toxicity) to determine pharmacokinetics profile against cancer. Docking is carried out against pTEN and HBx proteins, as a target to evaluate the binding complex based on their binding score, residues in binding pockets and hydrogen bonds involved. Furthermore, the protein-ligand complex molecular dynamics simulation is conducted with the best binding score to ascertain the complex binding stability over a period of time.

\section{Materials And Methods}

\subsection{The selected compounds study for Drug likeness parameters}

The Lipinski rule of five, known as Ro5 is used to estimate the permeability and solubility of the mentioned compounds which help in understanding their suitability for oral bioavailability [19]. The drug likeness was evaluated by utilizing an online server tool name Molinspiration (http://www.molinspiration.com). Ro5 predicts the poor permeation and absorption when the criteria are more likely:

a). Greater than Ten Hydrogen Bond Acceptor (HBA).

b). Molecular weight greater than $500 \mathrm{kDa}$.

c). More than 5 Hydrogen Bond Donor (HBD).

d). Should be more than five the octanol-water potential $(X \log P) /$ Moriguchi $\log P(M \log P>4.15)$. 
e). Antibody, vitamins, antifungal etc. are exceptional to this rule that belong to the classes of substrates for biological transporters.

\subsection{ADMET profiling of the bioactive compounds}

The compounds satisfying the rule of five are screened out and further investigated for their pharmacokinetics parameters. The criteria include the analysis of the properties of compounds like Toxicity, Absorption, Distribution, Metabolism and Excretion in the human system. The online server PreADMET is used for this parameter study (https://preadmet.bmdrc.kr/). Mutagenicity is predicted using the Ame's Test while carcinogenicity model is based on carcinogenic test on mice and rats for two years. The aspects we consider in our studies include parameters like skin permeability, Caco-2 permeability, mutagenicity, carcinogenicity, Human Intestinal Absorption (\% HIA), MDCK cell permeability, cytochrome P450 2D6 metabolism and blood-brain barrier penetration.

\subsection{Target protein structure preparation}

The three-dimensional structure of the protein pTEN (1D5R) and HBx (3MS6) are retrieved from the RCSB protein database (Research Collaboratory for Structural Bioinformatics) (www.rcsb.org). BIOVIA Discovery Studio tool is used to prepare the target in such a way that it has no ambiguities i.e., small molecules and water molecules are deleted. The ligand/substrate attached to the target protein and heteroatoms are removed. The structure is energy minimized to remove bad steric clashes using CHARMM force field. In this study, all the computation studies were conducted in vacuum phase.

\subsection{Preparation of ligand structure}

Seventeen bioactive compounds are selected in these studies, which are reported to be present in the $C$. oblonga seeds in various review literatures. The compounds structures are retrieved from the PubChem compound database and later converted to its 3D PDB structure via Discovery Studio 2.5 software where it was energy minimized. Furthermore, gasteiger partial charges were added and CHARMM force field and MMFF94x partial charge were applied to optimize the structures. Using the RMS gradient energy, structure is further minimized with $0.001 \mathrm{kcal} / \mathrm{mol}$, although other parameters are maintained by default.

\subsection{Molecular docking of ligands with pTEN (TSG) and HBx oncogene}

AutoDock tools (ADT) is one of the most cited in-silico tools in research field used for performing the docking experiment. This software uses the AMBER force field that include Genetic Algorithm and scoring function of Empirical free energy to explore the binding affinity between the target protein and ligand compound [20]. AutoDock is employed to execute docking simulations, generating ten conformations of ligand in complex with the target receptor, which were further filtered through their free binding energy score. The protein structure is parameterized by allocating atomic salvation parameters, Kollman charges, polar Hydrogen atoms, and fragmental volume while ligands were energy minimized using ADT. Four coordinate files are created that are ligand.pdbqt, receptor.pdbqt, grid.gpf and dock.dpf. The co-ordinates of $\mathrm{x}, \mathrm{y}$ and $\mathrm{z}$ axis of each grid point was established around $60 \times 60 \times 60 \AA$ and for $\mathrm{PTEN}$ the co-ordinates were positioned at $X=38.248, Y=82.41$ and $Z=31.742$, while for HBx it was set at $X=0.724, Y=9.825$ and $Z=9.071$ with a grid spacing between 2 connecting points was kept at $0.375 \AA$ of the grid. The molecular docking simulation for 150 population size were conducted using energy evaluations at 2500000 for a number of hundred GA (Genetic algorithm) for each ligand and RMSD (Root Mean Square Deviation) for each evaluation for docking was set at $2.0 \AA$ with 0.274 co-efficient of torsion degree of freedom were constitute for inhibitor molecules.

The molecular docking was accomplished using the Lamarckian genetic algorithm (LGA) and the remaining parameters were set to default with a 0.2 rate of mutation, 0.8 crossover rate with 27,000 numbers of maximum generations. The results were generated in .glg and .dlg file were further studied for the ligand and protein interaction. The results were clustered based on their binding energy, inhibition constant and intermolecular energy [21]. The vary protocol was performed on each ligand used in this investigation. The best docked result is compiled and structure were developed using the Discovery Studio Visualizer 3.5 and Pymol.

\subsection{Stability study of the protein-ligand complex by molecular dynamic simulation}


The ligands having highest free binding energy when docked against pTEN and HBx were further continued for its stability analysis using GROMACS 5.1 package software (GROningen MAchine for Chemical Simulations) [22]. SwissParam, the online server was utilized to create the ligand topology [23] and receptor protein topology was developed with the aid of the CHARMM27 all-atom force field within the framework of GROMACS functions. A water model of $3.0 \mathrm{~nm}$ distance TIP-3 points (TIP3P) to sustain the simulation under periodic boundary conditions was introduced from the protein to the box faces [24]. A dodecahedral box model with SPC water molecules was used for solvation and to prevent clashes of proteins, a margin of $10 \AA$ was applied with external boundaries [25]. In all simulation process, the solvated system is neutralized by adding sodium ions. To bring the maximum force below $1000 \mathrm{~kJ} / \mathrm{mol} / \mathrm{nm}$ about 2000 steps of steepest energy minimization was executed for removing the steric clashes for all the systems. The electrostatic interactions with long-range were evaluated by employing the method of Particle Mesh Ewald (PME) and the bond length was constraint by applying the LINCS (Linear constraint solver) algorithm [26], respectively. For the computation of the non-bonded interaction of Van-der Waals forces, applied cut-off of about $1.0 \mathrm{~nm}$ value [27]. Further, our system is equilibrated for 1000 picosecond under NVT at temperature of 300K (constant number of particles, volume, and temperature) followed by 1000 picoseconds NPT equilibration at a temperature of $300 \mathrm{~K}$ with a pressure of 1 bar. The temperature coupling was accomplished at a temperature of $300 \mathrm{~K}$ with a time constant of 0.1 picosecond by implementing velocity rescaling thermostat [28]. The algorithm provided by the Parrinello-Rahman barostat was implemented with a 1 picosecond constant to calculate the pressure at 1 bar [29].

Finally, the protein-ligand system was introduced to simulation of $100 \mathrm{~ns}$ of molecular dynamics (MD), performed under identical conditions at 1 bar and temperature of $300 \mathrm{~K}$. At each step, a Leap-frog integrator was applied throughout the MD simulation with a size of 2 femtoseconds and the resulted MD coordinates for further analysis were saved at an interval of every 2 picosecond [30]. The gmx rms, gmx rms, gmx sasa, gmx hbond and gmx gyrate module of GROMACS is used during the $100 \mathrm{~ns}$ long simulation to determine RMSD, RMSF (Root mean square deviation and Root Mean Square Fluctuation, respectively), solvent accessible surface area, number of hydrogen bonds involved and change in compactness using radius of gyration of protein backbone with reference to the atom's located at the initial positions in the backbone.

\section{Results}

\section{Drug likeness and bioactivity score}

The concept "drug-likeness" is emphasized in pharmaceutical research in recent years as it's believed that successful prediction of drug-like properties in early stage will pay off in the drug development at the later stages. The Lipinski rule of five, "Ro5" is the most favorable technique to identify the compounds that are similar to the conventional drug. If the violation is 0 or 1 , the compounds are assumed to bind effectively to the receptor and was rejected when the violation number exceeds 2 . Seventeen compounds that are present in $C$. oblonga seeds are selected (Table 1) for this study and are filtered through Lipinski rule, including the reference compound Doxorubicin. 
Table 1

In silico-based determination of pharmacokinetics of the selected compounds and Doxorubicin (Standard compound) using online server Molinspiration.

\begin{tabular}{|l|l|l|l|l|l|l|}
\hline $\begin{array}{l}\text { Sr. } \\
\text { No. }\end{array}$ & $\begin{array}{l}\text { Bioactive } \\
\text { compounds }\end{array}$ & $\begin{array}{l}\text { Molecular } \\
\text { weight } \\
(\mathrm{g} / \mathrm{mol})\end{array}$ & $\begin{array}{l}\text { Hydrogen bond acceptor } \\
\text { count (HBA) }\end{array}$ & $\begin{array}{l}\text { Hydrogen bond donor } \\
\text { count (HBD) }\end{array}$ & $\begin{array}{l}\text { XlopP } \\
\text { N } \\
\text { violations }\end{array}$ \\
\hline
\end{tabular}

\section{Reference Compound}

\begin{tabular}{|l|l|l|l|l|l|l|}
\hline 1. & Doxorubicin & 543.52 & 12 & 7 & 0.57 & 3 \\
\hline
\end{tabular}

Bioactive Compounds from $C$. oblonga

\begin{tabular}{|c|c|c|c|c|c|c|}
\hline 1. & $\begin{array}{l}\text { 3-O- caffeoylquinic } \\
\text { acid }\end{array}$ & 354.31 & 9 & 6 & -0.45 & 1 \\
\hline 2 . & $\begin{array}{l}\text { 4-O- caffeoylquinic } \\
\text { acid }\end{array}$ & 354.31 & 9 & 6 & -0.67 & 1 \\
\hline 3. & $\begin{array}{l}\text { 5-O- caffeoylquinic } \\
\text { acid }\end{array}$ & 354.31 & 9 & 6 & -0.45 & 1 \\
\hline 4. & $\begin{array}{l}\text { 3,5-O-di } \\
\text { caffeoylquinic acid }\end{array}$ & 516.46 & 12 & 7 & 1.42 & 3 \\
\hline 5. & Vicenin-2 & 594.52 & 15 & 11 & -2.10 & 3 \\
\hline 6. & Lucenin-2 & 610.52 & 16 & 12 & -2.59 & 3 \\
\hline 7. & Stellarin-2 & 624.55 & 16 & 11 & -2.28 & 3 \\
\hline 8. & Isoschaftoside & 564.50 & 14 & 10 & -1.68 & 3 \\
\hline 9. & Schaftoside & 564.50 & 14 & 10 & -1.68 & 3 \\
\hline 10. & Chrysoeriol & 300.27 & 6 & 3 & 2.28 & 0 \\
\hline 11. & $\begin{array}{l}\text { Kaempferol-3-O- } \\
\text { glucoside }\end{array}$ & 448.38 & 11 & 7 & 0.12 & 2 \\
\hline 12. & $\begin{array}{l}\text { Kaempferol-3-O- } \\
\text { rutinoside }\end{array}$ & 578.52 & 14 & 8 & -0.10 & 3 \\
\hline 13. & $\begin{array}{l}\text { Quercetin-3-O- } \\
\text { galactoside }\end{array}$ & 464.38 & 12 & 8 & -0.36 & 2 \\
\hline 14. & $\begin{array}{l}\text { Quercetin-3-O- } \\
\text { glucoside }\end{array}$ & 464.38 & 12 & 8 & -0.36 & 2 \\
\hline 15. & $\begin{array}{l}\text { Quercetin-3-O- } \\
\text { rutinoside }\end{array}$ & 610.52 & 16 & 10 & -1.06 & 3 \\
\hline 16. & Catechin & 290.27 & 6 & 5 & 1.37 & 0 \\
\hline 17. & Mangiferin & 422.34 & 11 & 8 & -0.16 & 2 \\
\hline
\end{tabular}


Only 5 of these compounds including 3CQA (3-O- caffeoylquinic acid), Catechin, 4CQA (4-O- caffeoylquinic acid), Chrysoeriol and 5CQA (5-O- caffeoylquinic acid) are screened which follows the Lipinski drug likeness criteria and hence they are continued for further evaluations. Compounds that debased the Lipinski's rules more than once could have a bioavailability complication.

Two of our filtered compounds Chrysoeriol and Catechin show better bioavability in comparison to the standard drug Doxorubicin. The drug is expected to bind the biological targets; thus, bioactivity of the compounds contributes to the overall potential to qualify the compounds as a drug that are determined by the combination of kinase inhibitor, G-protein-coupled receptor, protease and enzyme inhibitor, ion channel modulators and nuclear receptor ligands. According to the general concept, greater the bioactivity scores the probability of being biologically active of the individual compound is higher (Table 2). If the bioactivity score for the metal complexes is higher than 0.0 , then the complex is believed to be biologically active and if its value lies between -5.0 and 0.0 , then the complex is active moderately while the compounds trusted to be inactive when bioactivity score lies below -5.0 [31]. 3CQA, 4CQA and 5CQA acids shows highly bioactive towards the nuclear receptor ligand. All our compounds show moderate activity toward other biological receptors (>-0.50). The results demonstrate that 3CQA and 5CQA shows better bioactivity score than doxorubicin.

Table 2

Bioactivity score of the bioactive compounds and its complex evaluated using online server Molinspiration.

\begin{tabular}{|c|c|c|c|c|c|c|c|}
\hline $\begin{array}{l}\text { Sr. } \\
\text { No. }\end{array}$ & Compounds & GPCR & $\begin{array}{l}\text { Ion channel } \\
\text { modulator }\end{array}$ & $\begin{array}{l}\text { Kinase } \\
\text { inhibitor }\end{array}$ & $\begin{array}{l}\text { Nuclear receptor } \\
\text { ligand }\end{array}$ & $\begin{array}{l}\text { Protease } \\
\text { inhibitor }\end{array}$ & $\begin{array}{l}\text { Enzyme } \\
\text { inhibitor }\end{array}$ \\
\hline 1. & Doxorubicin & 0.20 & -0.20 & -0.07 & 0.32 & 0.67 & 0.66 \\
\hline 2. & $\begin{array}{l}\text { 3-O- } \\
\text { caffeoylquinic } \\
\text { acid }\end{array}$ & 0.29 & 0.14 & -0.00 & 0.74 & 0.27 & 0.62 \\
\hline 3. & $\begin{array}{l}\text { 4-O- } \\
\text { caffeoylquinic } \\
\text { acid }\end{array}$ & 0.18 & 0.02 & -0.10 & 0.66 & 0.14 & 0.49 \\
\hline 4. & $\begin{array}{l}\text { 5-O- } \\
\text { caffeoylquinic } \\
\text { acid }\end{array}$ & 0.29 & 0.14 & -0.00 & 0.74 & 0.27 & 0.62 \\
\hline 5. & Chrysoeriol & -0.05 & -0.14 & 0.25 & 0.32 & -0.26 & 0.21 \\
\hline 6. & Catechin & 0.41 & 0.14 & 0.09 & 0.60 & 0.26 & 0.47 \\
\hline
\end{tabular}

\section{ADMET prediction of the compounds in comparison with the conventional drug Doxorubicin}

Unwanted ADMET properties of the new drug candidate are one of the reasons for many developmental failures hence to survive the phase I clinical trials these problems required to be identify in earlier stages of processes. The hurdle encounter in traditional ADME and toxicity testing is (multistep and time-consuming) is addressed by employing combinatorial chemistry and computation studies. Hence for the determination of pharmacokinetics or pharmacology properties of the compound, several chemical parameters were evaluated to determine their compliance with the standard range by using in silico tools. Those properties comprise of blood-brain barrier penetration, aqueous solubility, MDCK cell permeability, Human Intestinal Absorption (\% HIA), Toxicity, Caco-2 and skin permeability and Cytochrome P450 2D6 binding. These properties were projected to be essential for the invention of novel bioactive compounds, thus on investigate the failure of lead competitors that will cause toxicity in its inactive form or one can possibly penetrate the intestinal layer. Thus, on the basis of the evaluation our compounds show mutagenicity and moderate absorption/permeation properties, though doxorubicin is non-mutagenic but is carcinogenic in both 
mouse and rat. CQA shows non-carcinogenicity in mouse and carcinogenicity in rat (except 4-O-caffeoylquinic acid is non carcinogenic in both rat and mice), whereas catechin is carcinogenic in both mouse and rats (Table 3). Our compounds have values below one for BBB which shows its inactivity for central nervous system and PPB below 90 that represents weak interaction (except catechin that shows strong bonding) with PPB. Thus, from the interpretation of our results 3CQA, 4CQA, 5CQA and Chrysoeriol shows the promising results and are further evaluated for docking and its stability.

Table 3

The ADMET profiling of the bioactive compounds and the reference compound (doxorubicin) using online server tool PreADMET.

\begin{tabular}{|c|c|c|c|c|c|c|c|c|c|c|}
\hline \multirow{3}{*}{ Compounds } & \multicolumn{3}{|l|}{ Toxicity } & \multicolumn{4}{|c|}{ Absorption } & \multicolumn{2}{|c|}{ Distribution } & Metabolism \\
\hline & \multirow[t]{2}{*}{ Mutagenicity } & \multicolumn{2}{|c|}{ Carcinogenicity } & \multirow[t]{2}{*}{ HIA } & \multirow[t]{2}{*}{ Caco2 } & \multirow[t]{2}{*}{ MDCK } & \multirow[t]{2}{*}{ Skin } & \multirow[t]{2}{*}{ PPB } & \multirow[t]{2}{*}{ BBB } & \multirow[t]{2}{*}{ CYP2D6 } \\
\hline & & Mouse & Rat & & & & & & & \\
\hline
\end{tabular}

\section{Reference Compound(s)}

\begin{tabular}{|l|l|l|l|l|l|l|l|l|l|l|}
\hline $\begin{array}{l}\text { Doxorubicin } \\
(31703)\end{array}$ & NM & C & C & 31.95 & 17.73 & 1.02 & -4.69 & 32.79 & 0.03 & NON \\
\hline
\end{tabular}

\section{Bioactive compounds in Cydonia oblonga seeds}

\begin{tabular}{|l|l|l|l|l|l|l|l|l|l|l|}
\hline $\begin{array}{l}\text { 3-O- } \\
\text { caffeoylquinic } \\
\text { acid } \\
(1794427)\end{array}$ & M & NC & C & 20.427 & 18.71 & 4.51 & -3.89 & 41.96 & 0.033661 & NON \\
\hline $\begin{array}{l}4-O- \\
\text { caffeoylquinic } \\
\text { acid } \\
(5315599)\end{array}$ & M & NC & NC & 20.427 & 19.6166 & 0.746 & -3.895 & 43.977 & 0.0331 & NON \\
\hline $\begin{array}{l}5-O- \\
\text { caffeoylquinic } \\
\text { acid } \\
\text { (5280633) }\end{array}$ & M & NC & C & 20.427 & 18.71 & 4.51 & -3.89 & 41.96 & 0.0336 & NON \\
\hline $\begin{array}{l}\text { Chrysoriol } \\
(5280666)\end{array}$ & M & C & NC & 88.18 & 5.18 & 37.45 & -4.14 & 90.87 & 0.088 & NON \\
\hline $\begin{array}{l}\text { Catechin } \\
(73160)\end{array}$ & M & C & C & 66.707 & 0.656 & 44.38 & -4.29 & 100.00 & 0.39 & NON \\
\hline
\end{tabular}

\section{Molecular docking of the ligands and standard drug with pTEN and HBx protein}

For the better understanding protein-ligand complex structural basis, molecular docking was carried out using AutoDock Tool 4.2 which is a very convenient and cheap tool to study protein-ligand interactions. The results output files provide the free binding energy of all ten conformation for each protein-ligand interaction which is utilized to generate the best docked complex. 3CQA, 4CQA, 5CQA and Chrysoeriol are the compounds concealed after the pharmacokinetic determination. These compounds are docked against PTEN and HBx along with the standard drug doxorubicin. The docked result of the standard drugs shows the free 
energy of binding, -3.46 and $-5.69 \mathrm{kcal} / \mathrm{mol}$ with inhibition constant of $2.92 \mathrm{mM}$ and $67.50 \mathrm{uM}$ with pTEN and HBx, respectively. The caffeoylquinic acid derivatives shows the best binding affinity against pTEN (-7.53, -7.42, -7.49 of 3CQA, 4CQA and 5CQA, respectively) while HBx shows somewhat similar affinity with all the ligands (3CQA, 4CQA, 5CQA and Chrysoeriol, respectively shows $-5.94,-5.87,-6.01$ and -5.83 , respectively) (Table 4).

Table 4

AutoDock score of the ligands and doxorubicin against both pTEN and HBx.

\begin{tabular}{|l|l|l|l|l|}
\hline \multirow{2}{*}{ Bioactive compounds } & \multicolumn{2}{l}{ pTEN (1D5R) } & \multicolumn{2}{l|}{ HBx (3MS6) } \\
\cline { 2 - 5 } & $\begin{array}{l}\text { Free Energy of Binding } \\
\text { (kcal/mol) }\end{array}$ & $\begin{array}{l}\text { Inhibition } \\
\text { Constant, Ki }\end{array}$ & $\begin{array}{l}\text { Free Energy of } \\
\text { Binding }\end{array}$ & $\begin{array}{l}\text { Inhibition } \\
\text { Constant, Ki }\end{array}$ \\
\hline Doxorubicin (31703) & -3.46 & $2.92 \mathrm{mM}$ & -5.69 & $67.50 \mathrm{uM}$ \\
\hline $\begin{array}{l}\text { 3-O- caffeoylquinic acid } \\
\text { (1794427) }\end{array}$ & -7.53 & $3.03 \mu \mathrm{M}$ & -5.94 & $44.33 \mathrm{uM}$ \\
\hline $\begin{array}{l}\text { 4-O- caffeoylquinic acid } \\
\text { (5315599) }\end{array}$ & -7.42 & $2.58 \mu \mathrm{M}$ & -5.87 & $49.51 \mathrm{uM}$ \\
\hline $\begin{array}{l}\text { 5-O-caffeoylquinic acid } \\
\text { (5280633) }\end{array}$ & -7.49 & $3.24 \mu \mathrm{M}$ & $-6.01 \mathrm{kcal} / \mathrm{mol}$ & $39.54 \mathrm{uM}$ \\
\hline Chrysoeriol (5280666) & -6.90 & $8.74 \mu \mathrm{M}$ & -5.83 & $39.91 \mathrm{uM}$ \\
\hline
\end{tabular}

The residues that are reported to be present at the active site in PTEN are HCXXGXXR motifs, while the residue Cys-124 and Arg130 plays a critical role in pTEN catalytic activity and residue His-123 and Gly-127 are essential for the conformation P-lop of pTEN [32,33]. Additionally, Asp-92 residue present in "WPD" loop of pTEN behaves as basic acid to promote the phenolic oxygen protonation of the tyrosyl leaving group [34]. On the other hand, the binding pocket of HBx in the novel structure 3 MS6 contain residues Leu-5, His-8, Thr-12, Thr-12, Thr-36, His-41, Glu-68, Ser-69, Asp-70, Asn-71, Ile-74, His-79, Asp-80 and His-87. The detailed evaluation of the binding pockets of caffeoylquinic acid derivatives with both pTEN and HBx is given in Table 5. As we compare the binding pocket of our docked results (Fig. 1 and Fig. 2) the residues involved in Doxorubicin are ALA126, ASP92, ARG130, CYS124, GLY127, GLY129, HIS93, ILE168, LYS125, LYS128, LYS330, THR167 and similar residues are seen in other ligands binding pockets (Fig. 1) against docking with protein PTEN. Hence this shows that are ligands are binding in the vary pocket where the novel pTEN (1D5R) structure reported to have active sites. Our standard complex with pTEN shows 5 hydrogen bond interactions while caffeoylquinic acid derivatives shows hydrogen bonding more than Doxorubicin-pTEN complex, which also attributes to the stability of the complex. 
Table 5

Active site pocket residues and Hydrogen bonds interaction between protein pTEN (1D5R) and ligand revealed through molecular docking

\begin{tabular}{|c|c|c|c|c|}
\hline \multirow[t]{2}{*}{ Compounds } & \multicolumn{2}{|c|}{$\begin{array}{l}\text { Hydrogen bonds between protein and } \\
\text { ligand }\end{array}$} & \multicolumn{2}{|l|}{ Residues } \\
\hline & pTEN & HBx & pTEN & $\mathrm{HBx}$ \\
\hline Doxorubicin & $\begin{array}{l}\text { A:ALA126:HN } \\
-: \text { UNK0:O7 } \\
\text { A:LYS128:HN } \\
-: U N K 0: O 7 \\
\text { A:ARG130:HH21 } \\
-: U N K 0: O 8 \\
: U N K 0: H 63- \\
\text { A:ASP92:OD2 }\end{array}$ & $\begin{array}{l}: \text { UNK0:H55 -:THR12:OG1 } \\
: \text { UNK0:H61 - A: VAL84: } \\
\text { O } \\
\text { A:ILE76:HN3-:UNK0:O10 } \\
\text { A:HIS79:HE2:B - } \\
: \text { UNK0:O6 }\end{array}$ & $\begin{array}{l}\text { ASP92, HIS93 CYS124, } \\
\text { LYS125, ALA126, GLY127, } \\
\text { LYS128, GLY129, ARG130, } \\
\text { THR167, ILE168, LYS330 }\end{array}$ & $\begin{array}{l}\text { HIS8, THR12, } \\
\text { ASN15, ILE18, } \\
\text { VAL65, CYS66, } \\
\text { ASN73, ILE74, } \\
\text { ILE76, GLN77, } \\
\text { HIS79, VAL84, } \\
\text { ALA85, VAL86, } \\
\text { LYS88 }\end{array}$ \\
\hline $\begin{array}{l}\text { 3-O- } \\
\text { caffeoylquinic } \\
\text { acid }\end{array}$ & $\begin{array}{l}\text { A:HIS93:HE2 - } \\
\text { :UNK0:O3 } \\
\text { A:CYS124:SG - } \\
\text { :UNK0:O8 } \\
\text { A:ALA126:HN - } \\
\text { :UNK0:O9 } \\
\text { A:LYS128:HZ3 - } \\
\text { :UNK0:O7 } \\
\text { A:ARG130:HN - } \\
: U N K 0: O 8 \\
\text { A:ARG130:HE - } \\
: U N K 0: O 8 \\
\text { A:ARG130:HH21 } \\
\text { - :UNK0:O9 } \\
\text { A:LYS330:HZ3 - } \\
: U N K 0: O 2 \\
\text { A:LYS330:HZ3 - } \\
: U N K 0: O 5 \\
: U N K 0: H 36 ~-~ \\
\text { A:ASP326:O } \\
: U N K 0: H 42 ~-~ \\
\text { A:CYS124:SG }\end{array}$ & $\begin{array}{l}: U N K 0: H 34-A: \text { VAL84: O } \\
: U N K 0: H 42- \\
\text { A:THR12:OG1 } \\
: U N K 0: H 43- \\
\text { A:THR12:OG1 } \\
\text { A:ILE76:HN3 - :UNK0:O3 } \\
\text { A:ILE76:HN3 - :UNK0:O4 } \\
\text { A:HIS79:HE2:B - } \\
: \text { UNK0:O1 } \\
\text { A:HIS79:HE2:B - } \\
: U N K 0: O 7 \\
\text { A:LYS88:HZ3 - :UNK0:O5 }\end{array}$ & $\begin{array}{l}\text { ASP92, HIS93, CYS124, } \\
\text { LYS125, ALA126, GLY127, } \\
\text { LYS128, GLY129, ARG130, } \\
\text { THR131, THR167, ILE168, } \\
\text { GLN171, ASP326, LYS327, } \\
\text { ASN329, LYS330 }\end{array}$ & $\begin{array}{l}\text { HIS8, THR12, ILE76, } \\
\text { GLN77, HIS79, } \\
\text { VAL84, ALA85, } \\
\text { VAL86, LYS88 }\end{array}$ \\
\hline
\end{tabular}




\begin{tabular}{|c|c|c|c|c|}
\hline \multirow[t]{2}{*}{ Compounds } & \multicolumn{2}{|c|}{$\begin{array}{l}\text { Hydrogen bonds between protein and } \\
\text { ligand }\end{array}$} & \multicolumn{2}{|l|}{ Residues } \\
\hline & pTEN & HBx & pTEN & HBx \\
\hline $\begin{array}{l}\text { 4-O- } \\
\text { caffeoylquinic } \\
\text { acid }\end{array}$ & $\begin{array}{l}\text { A:HIS93:HE2 - } \\
\text { :UNK0:O4 } \\
\text { A:CYS124:SG - } \\
\text { :UNK0:O6 } \\
\text { A:ALA126:HN - } \\
\text { :UNK0:O6 } \\
\text { A:LYS128:HN - } \\
: \text { UNK0:O6 } \\
\text { A:LYS128:HZ3 - } \\
: U N K 0: O 7 \\
\text { A:ARG130:HH21 } \\
-: U N K 0: O 5 \\
\text { A:LYS330:HZ3 - } \\
\text { :UNK0:O8 } \\
: U N K 0: H 33- \\
\text { A:ASP92:OD2 } \\
: U N K 0: H 42 ~-~ \\
\text { A:ASP326:O }\end{array}$ & $\begin{array}{l}\text { :UNK0:H35 - A: VAL84: } \\
\text { O } \\
\text { A:ILE76:HN3 - :UNK0:O2 } \\
\text { A:ILE76:HN3 - :UNK0:O5 } \\
\text { A:HIS79:HE2:B - } \\
: \text { UNK0:O1 } \\
\text { A:HIS79:HE2:B - } \\
: \text { UNK0:O4 } \\
\text { A:VAL86:HN - :UNK0:O6 }\end{array}$ & $\begin{array}{l}\text { ASP92, HIS93, CYS124, } \\
\text { LYS125, ALA126, GLY127, } \\
\text { LYS128, GLY129, ARG130, } \\
\text { THR167, ILE168, GLN171, } \\
\text { ASP326, LYS327, ASN329, } \\
\text { LYS330 }\end{array}$ & $\begin{array}{l}\text { LEU5, HIS8, LEU9, } \\
\text { THR12, VAL64, } \\
\text { VAL65, ILE74, } \\
\text { ILE76, GLN77, } \\
\text { HIS79, VAL84, } \\
\text { ALA85, VAL86 }\end{array}$ \\
\hline
\end{tabular}




\begin{tabular}{|c|c|c|c|c|}
\hline \multirow[t]{2}{*}{ Compounds } & \multicolumn{2}{|c|}{$\begin{array}{l}\text { Hydrogen bonds between protein and } \\
\text { ligand }\end{array}$} & \multicolumn{2}{|l|}{ Residues } \\
\hline & pTEN & HBx & pTEN & HBx \\
\hline $\begin{array}{l}\text { 5-O- } \\
\text { caffeoylquinic } \\
\text { acid }\end{array}$ & $\begin{array}{l}\text { :UNK0:H33 - } \\
\text { A:THR167:OG1 } \\
\text { :UNK0:H36 - } \\
\text { A:THR167:OG1 } \\
: \text { UNK0:H42 - } \\
\text { A:CYS124:SG } \\
\text { A:CYS124:SG - } \\
\text { :UNK0:O8 } \\
\text { A:ALA126:HN - } \\
\text { :UNK0:O9 } \\
\text { A:LYS128:HZ3 - } \\
: U N K 0: O 7 \\
\text { A:ARG130:HN - } \\
: U N K 0: O 8 \\
\text { A:ARG130:HE - } \\
: U N K 0: O 8 \\
\text { A:ARG130:HH21 } \\
- \text { :UNK0:O9 } \\
\text { A:THR167:HG1 - } \\
: U N K 0: O 2 \\
\text { A:LYS330:HZ1 - } \\
\text { :UNK0:O2 } \\
\text { A:LYS330:HZ1 - } \\
\text { :UNK0:O5 }\end{array}$ & $\begin{array}{l}\text { A:THR12:HG1 - } \\
: U N K 0: O 8 \\
\text { A:ILE76:HN1 - :UNK0:O4 } \\
\text { A:ILE76:HN3 - :UNK0:O3 } \\
\text { A:HIS79:HE2:B - } \\
: \text { UNK0:O7 } \\
\text { A:VAL86:HN - :UNK0:O4 } \\
\text { A:LYS88:HZ3 - :UNK0:O5 } \\
: \text { UNK0:H35 - A: VAL86: } \\
\text { O }\end{array}$ & $\begin{array}{l}\text { ASP92, HIS93, CYS124, } \\
\text { LYS125, ALA126, GLY127, } \\
\text { LYS128, GLY129, ARG130, } \\
\text { THR131, THR167, ILE168, } \\
\text { GLN171, LYS330 }\end{array}$ & $\begin{array}{l}\text { HIS8, LEU 9, THR12, } \\
\text { VAL21, ILE74, } \\
\text { ILE76, GLN77, } \\
\text { HIS79, VAL84, } \\
\text { ALA85, VAL86, } \\
\text { LYS88 }\end{array}$ \\
\hline
\end{tabular}

The pocket residues involve in HBx-doxorubicin complex (Table 5) are HIS8, ASP11, THR12, ASN15, ILE18, VAL65, CYS66, ASN73, ILE74, ILE76, GLN77, HIS79, VAL84, ALA85, VAL86 and LYS88; and 4 hydrogen bonds. Similarly, HIS8, THR12, ILE76, GLN77, HIS79, VAL84, ALA85, VAL86 and LYS88 are present in HBx-3-O- caffeoylquinic acid; LEU5, HIS8, LEU9, THR12, VAL64, VAL65, ILE74, ILE76, GLN77, HIS79, VAL84, ALA85 and VAL86 in HBx-4CQA and HBx-5CQA contain HIS8, LEU9, THR12, VAL21, ILE74, ILE76, GLN77, HIS79, VAL84, ALA85, VAL86 and LYS88 in the binding pocket with 8, 6 and 7 hydrogen bonds respectively (Fig. 2). Hence it can be concluded that the binding of the ligands is in the similar pocket region as our standard drugs doxorubicin is binding with the HBx.

\section{Molecular dynamics simulation to analyze the complex stability}

Initially, our docking results revealed that the screened compounds including 3CQA, 4CQA, 5CQA and Chrysoeriol could be potential inhibitors. 3CQA and 5CQA were, however, seen to be promising. Therefore, we employed MD simulation for better comprehending the molecular mechanism which may be involved in the analysis. An unbiased simulation was performed for each of the two protein-ligand complexes. A valuable insight was provided by the $100 \mathrm{~ns}$ long MD simulation related to the pTEN and $\mathrm{HBx}$ structural dynamics with different ligand compounds. For example, the energy of interaction between proteins and ligands illustrates the profound binding between them and well-built interactions between them are characterized by the higher number of hydrogen bonds. 
MD trajectories were analyzed for all the related atoms in the backbone and ligands for RMSD determination and assessment of average fluctuations i.e., the RMSF of each residue of the protein in a time-dependent manner for all molecules in the backbone. One of the key criteria for testing the equilibrium of MD directions is the RMSD. To begin with, we determined the RMSD from the initial docked position of the individual compound. The smaller the variance, the individual compounds have a better docked conformation. In other words, during computation, the ligand remains in its initial conformation. The average RMSD value of pTEN with 3CQA and 5CQA for $100 \mathrm{~ns}$ trajectory calculated to be $0.245 \mathrm{~nm}$ and $0.215 \mathrm{~nm}$, respectively. At first, there is a small fluctuation in the trajectory but later the degree of fluctuation reaches equilibrium (Fig. 3 (a)). The pTEN complexes with 3CQA shows high level of fluctuation in a residue at a position 1-29, 504-518, 1041-1098, 1673, 1681, 3212-3217 and 4093-4115, while 5CQA shows high level of fluctuation in residue position at 1-29, 1086-1098, 3203, 3210 and 4062-4134, with average fluctuation to be $0.107 \mathrm{~nm}$ and $0.114 \mathrm{~nm}$, respectively. The standard drug complex pTEN-Doxorubicin (pTEN-Dox) average RMSD value determine to be $0.213 \mathrm{~nm}$ with large number of residues showing high level fluctuation at position 1-53, 3201-3214 and $4081-4117$ with average RMSF value about $0.100 \mathrm{~nm}$. The residue at position between 4093 to 4115 shows the highest fluctuation in all the pTEN complexes. In comparison with standard, pTEN-5CQA shows more stability than pTEN-3CQA and pTEN-Dox as they have less variation throughout the $100 \mathrm{~ns}$ simulation and the system reaches equilibrium after $10 \mathrm{~ns}$ as compared to pTEN-Dox approximately and pTEN-3CQA. However, the system pTEN-5CQA shows higher flexibility followed by pTEN-3CQA complex and lastly pTEN-Dox complex system (Fig. 3 (c)).

The standard-HBx complex system have average RMSD value about $0.376 \mathrm{~nm}$, which reaches equilibrium after $30 \mathrm{~ns}$. However, HBx-Dox complex shows higher deviation and lowest flexibility compare to HBx-3CQA and HBx-5CQA complex system Fig. 3(b) \& 3(d). The residue with highest fluctuation values includes 1-20, 823-847, 916-946 and 968-998, while the complex has average RMSF value to be 0.139 . The RMSD value for HBx complexes with 3CQA and 5CQA has average fluctuations about $0.336 \mathrm{~nm}$ and $0.352 \mathrm{~nm}$, respectively and the complex system reaches to equilibrium after 30-40 ns. The residue at position 1-30, 345-347, 733851, 914-925 and 968-1005 shows high level of fluctuation in HBx-3CQA and at residue 1-20, 172, 190 and 797-821 in HBx-5CQA complex system with the highest deviation. The RMSF graph of HBx with ligands shows an increase in fluctuation compare to Doxorubicin, which might be due to the ligand adjustment in the binding pocket. Whereas, HBx-3CQA shows higher fluctuation in residues than to HBx-5CQA complex at the active region compare to the standard RMSF.

\section{Protein compactness and Hydrogen bond analysis}

The compactness and the folding behavior of the protein during the simulation is analyzed by utilizing the structural parameters of the 3D protein for computing the Radius of gyration $(\mathrm{Rg})$, which provides insight to the protein packaging during the simulation time period [35]. The average Rg for pTEN with ligand 3CQA and 5CQA complexes calculated to be 2.242 and $2.237 \mathrm{~nm}$, respectively. Similarly, the HBx ligand complexes has $1.268 \mathrm{~nm}$ and $1.260 \mathrm{~nm}$ average $\mathrm{Rg}$ value, respectively. The Rg plot of pTEN and $\mathrm{HBx}$ of ligands shows the decreased Rg value compare to the standard pTEN-Dox complex (2.234 nm) and Hbx-Dox complex $(1.285 \mathrm{~nm})$. However, there is no structural shift observed in pTEN after ligand binding compare to HBx protein and thus suggesting the higher stability of the ligand complexes compare to standard complexes throughout the trajectory (Fig. 4(a) \& (b)).

To evaluate the dynamic of protein folding-unfolding under the solvent environment, SASA plot (solvent-accessible surface area) was calculated and investigated [36]. The average SASA value of PTEN with Dox, 3CQA and 5CQA were calculated as 17.309, 17.334 and $17.407 \mathrm{~nm}$, respectively. Similarly, the HBx protein SASA against standard and ligand (3CQA and 5CQA) computed as $8.645,8.597$ and $8.634 \mathrm{~nm}$, respectively. The SASA pots shows a slight raise in protein-ligand complex compare to standard, which is possibly due to the exposure of some surface residues. However, it immediately reached equilibrium after $1 \mathrm{~ns}$ without any shift in structure during the whole run, depicting the protein stability before and after the ligand binding (Fig. 4 (c) \& (d)).

To validate the complex stability the intramolecular bonds of hydrogens also play a key role [37]. The intramolecular hydrogen bonds within $0.35 \mathrm{~nm}$ dynamics were determined in protein pTEN and HBx. The number of hydrogen bonds in pTEN with Dox, 3CQA and 5CQA had maximum 236, 238 and 238, respectively and that of HBx complexes were computed to be maximum around 61, 66 and 67, respectively. The pTEN-ligand and Hbx-ligand complex shows a slight increase in intramolecular bonds compare to the Doxorubicin complex of both proteins, which is suspected due to the protein's higher compactness (Fig. $\mathbf{5}$ (a) \& (b)). Similarly, the intermolecular hydrogen bonds show the similar number of bonds supporting the molecular docking analysis. The number of bonds involve in protein and compounds binding pocket to be around 4 to 6 for all complexes. Hence, supporting higher stability 
of the ligand complexes in comparison to the standard drug Doxorubicin throughout the trajectory (Fig. $\mathbf{5}$ (c) \& (d)). Hence, the docking and dynamics analysis of the hydrogen bonds depict that binding of 3-CQA and 5CQA with pTEN and HBx is more significantly stable than that with the protein-Dox as there are least variation in system throughout the $100 \mathrm{~ns}$ simulation.

\section{Discussion}

The plant kingdom contains high levels of phenols, which are known for their biological activities (like antioxidant, anti-diabetic, antibacterial, antiviral, anticancer and many more). Although, their health benefits reported from decades, studies concerning including biochemistry, analytical chemistry, biomedicine, etc. of these compounds are limited. Within this framework, many researches are attracted towards the un-investigated plant species to find novel compounds to combat diseases including cancer, diabetes mellitus and Alzheimer. The plants that are especially used in folklore medicines are extensively studied and identified for their bioactive compounds having selective apoptosis inducing activity and growth arrest of cancerous cells with minimum side effects. For example, cinnamic acid derivatives, ferulic acids, caffeic acid is stated to modulate signaling pathways for survival and proliferation, such as MAPK and PI3K-Akt [38]. Hepatotoxicity caused by drugs and alcohol consumption are the critical reason for liver damage. The most common drugs including amoxicillin-clavulanate, azathioprine and infliximab are the implicated agent resulting in drug-induced liver injury. Amoxicillin-clavulanate mediated liver injury was observed to occur in one out of 2300 users in latest prospective research, approximately [39].

Unlike other cancers, many oncogenes and TSG are engaged in hepatocarcinogenesis [40] in which pTEN, p53, TGF-a, IGF-2 and Myc are some genes that are altered in HCC [41]. A study conducted in China, lower pTEN expression are associated with grade of tumor and stage of disease and metastasis which correlates with enlarged tumor size and higher mortality rate [42]. Therefore, to define the stage of cancer and to ascertain the prognosis of HCC in patients, the level of pTEN expression can be exploited. HBx plays a central role in the development of tumorigenesis; HBV-associated liver disease is involved in the transition from chronic hepatitis and cirrhosis to HCC through stimulating intercellular signaling pathways. HBx mainly mediates by interacting with constituents in the liver tumor microenvironment including liver cancer cells, hepatic stellate cells, inflammatory cytokines, immune cells, exosomes and HIF-1 a [43]. In HCC advancement, overt participation of HBx oncogene has also been implicated. $\mathrm{HBx}$ directly disrupts the p53-mediated transcription of pTEN [44]. About $36 \%$ of HCC patients show higher expression of $\mathrm{HBx}$ protein; this can be utilized as a useful marker in HCC diagnosis. Activation of pTEN or suppression of HBx may be considered for a targeted therapy as an active approach against human HCC by the bioactive compounds.

Thus, for this purpose in-silico tools were utilized in selecting and forecasting the bioactive compounds of $C$. oblonga for their HCC potential. Quince seed have been studies for its therapeutically bioactive compounds which include 3CQA, 4CQA, 5CQA, diCQA, apigenin and chrysoeriol derivatives, stellarin-2 and leucenin-2 [45]. The AutoDock Tools 4.0 has successfully screened 3CQA and 5CQA bioactive compounds of $C$. oblonga by targeting pTEN and HBx proteins, before performing any expensive wet laboratory studies, recommending them as a potent anti-cancer agent for HCC management.

Several studies have been conducted to discover the biological attributes of $C$. oblonga and it derived bioactive compound caffeoylquinic acid derivatives, both in-vitro and in-vivo. An in-vivo experiment demonstrated about the protective role of aqueous extract of quince fruit in diethylnitrosamine (DEN) induced HCC rats, was reported by Adiban and his colleagues (2016) which shows remarkable reduction in serum biomarkers cancer and liver damage [46]. Caffeoylquinic acid (CQA) and its derivatives consumption stated to enhance antioxidant status, might increase colon motility and decrease colorectal cancer risk as they exhibit many physiological functions such as radical scavenging activities, anti-cancerous and antiproliferative activities [47]. The quince fruit methanolic extract (seed, pulp and peel) were analyzed for their antioxidant activity, shows significant free radical scavenging potential and antioxidant activities that organic acid fraction which is correlated with the caffeoylquinic acid content [48]. Similar study was conducted, to show the ability of isolated phenolics compounds from the methanolic extract of quince fruits, seeds and leaves to quench the DPPH (2,2'-diphenyl-1 picrylhydrazyl) free radicals and to inhibit the oxidative hemolysis results by 2,2'-azobis(2-amidinopropane) dihydrochloride in human erythrocytes [49] and comparatively, the seed extract shows the strongest antioxidant activity. Quince Aqueous Fermented Extract (QAFE) shows an effective anion superoxide radical (ID50 = $73.7 \mu \mathrm{g} / \mathrm{ml}$ ) and DPPH free radicals (ID50 $=68.80 \mu \mathrm{g} / \mathrm{ml}$ ) scavenging ability than Quince Wax Extract (QWE) which is comparatively more effective in preventing thiobarbituric reactive species (ID50=48.9 $\mu \mathrm{g} / \mathrm{ml}$ ) [50].

Page $14 / 22$ 
The docking result outcome of the 3CQA and 5CQA shows some promising results for targeting $\mathrm{PTEN}$ and HBx protein as a potent approach for targeted therapy. According to the Lipinski rule of five, 3CQA and 5CQA makes it a drug-like molecules except the negative value of Milog $\mathrm{P}$ i.e., poor solubility and permeability. However, in comparison with the standard drug doxorubicin it is quite similar (mentioned in Table 1). The ADMET profiling of 3CQA and 5CQA compounds Caco permeation, MDCK, BBB, HIA and Skin permeability was in harmony with the reference drug Doxorubicin. 3CQA and 5CQA shows mutagenicity and carcinogenic in rat model but non carcinogenic in mouse. However, the toxicity of reference drugs shows carcinogenicity in both mouse and rats but non-mutagenic in Ame's test. As we know all mutagen agents are not necessarily carcinogens, we consider that factor and continued the further docking studies. Previous experimental studies have already highlighted the activity of chlorogenic acid and its derivatives as an effective therapeutic compound for MMP-2 and MMP-9 suppression and prevents HCC prognosis by inactivation of ERK1/2 pathway [51].

The crystal structure of both pTEN and HBx was retrieved from RCSB protein data bank to perform the docking using AutoDock 4.0 tool. We conducted a comparative docking analysis of the 3CQA and 5CQA protein complex against the doxorubicin protein complex in this computational analysis. The binding affinity of all the ligands 3CQA, 5CQA, 5CQA and Chrysoeriol against pTEN is somewhat similar $-7.53,-7.42,-7.49$ and $-6.90 \mathrm{kcal} / \mathrm{mol}$, respectively and similar in case of $\mathrm{HBx}$ the variation in binding affinity is not large $-5.94,-5.87,6.01$ and $-5.83 \mathrm{kcal} / \mathrm{mol}$. The analysis shows that 3CQA and 5CQA have the best binding affinity against both pTEN and HBx protein when compared to standard drug doxorubicin with binding affinity -3.46 and $-5.69 \mathrm{kcal} / \mathrm{mol}$ and inhibition constant 2.92mM and $67.50 \mathrm{uM}$. Dysregulation of pTEN and HBx expression in HCC patients is correlated with advanced stage of metastasis and decreased life expectancy [42]. Subsequently, this computational study suggests that the $C$. oblonga phytochemicals especially 3CQA and 5CQA might show effective binding affinity with the target proteins pTEN and HBX respectively, as explained via AutoDock scoring function [52].

The $100 \mathrm{~ns}$ long MD simulation analysis disclosed that the complex stared 5CQA showing complex reaching equilibriumy after about 10 ns approximately and the ligand-pTEN complex systems show higher flexibility than standard-protein complex system but ligand-HBx system shows flexibility lower than the HBx-Dox as the fluctuations are quite higher comparatively to standard. Similarly, the Rg plot of p10 shows least deviation compare to HBx complexes, depicting the higher stability of p10 complexes than HBx complexes.

\section{Conclusion}

In developing countries about $70-95 \%$ of population depends on the traditional medicines and in market nearly $20-25 \%$ of modern drugs are derived from higher plants either directly or indirectly [53]. This attracts the scientist to exploit the traditional medicine system for cancer care. For example, "PHY906" is a Chinese herbal formulation which was approved in 2013 for phase II clinical trial in human [54]. From this study, it is clear that caffeoylquinic acid complex with pTEN shows significant binding affinity than with HBx protein target. In addition, incorporating Lipinski's drug likeness rule, bioactivity score, pharmacokinetics profiling and also molecular docking suggests that CQA plays an important therapeutic role compared to conventional drug doxorubicin. Therefore, 3CQA and 5CQA which also present in higher concentration in quince seed were taken for further molecular dynamic simulation. The simulation analysis based upon the RMSD and average hydrogen bonding affirms the stability of our complex 3CQA-pTEN, 5CQA-pTEN, 3CQA-HBx, and 5CQA-HBx that the standard drug doxorubicin. From these computational studies a conclusion is drawn that ligand 3CQA and 5CQA interacts with pTEN and HBx affirming to its anti-cancerous activity which are reported in many in-vitro studies mentioned above. Hopefully, a supportive hypothesis of developing HCC inhibitors will be put forward by the introduced compound. Thus, it might be a useful candidate for liver cancer prevention and care.

\section{Declarations}

Acknowledgement: The authors acknowledge the Office of Doctoral Studies and Research for critically reviewing the manuscript and providing the manuscript number (IU/R\&D/2020-MCN000982).

Funding: The authors declare that the research was conducted in the absence of any commercial or financial relationships that could be construed as a potential conflict of interest.

Page $15 / 22$ 
Competing interests: The authors declare that they have no conflicts of interest.

Ethical approval: Not required.

Availability of Data and Materials: Data can be made available upon request.

Code Availability: None

Author's contributions: EK has summarized, revised, edited and finalized the manuscript and work. IZA supervised the work and submitted the manuscript.

\section{References}

1. Gravitz L (2014) Liver cancer. Nature 516:S1-S1. https://doi.org/10.1038/516S1a

2. Mittal S, El-Serag HB (2013) Epidemiology of HCC: Consider the Population. J Clin Gastroenterol 47:1-10. https://doi.org/10.1097/MCG.0b013e3182872f29.Epidemiology

3. Fartoux L, Poujol-Robert A, Guéchot J, Wendum D, Poupon R, Serfaty L (2005) Insulin resistance is a cause of steatosis and fibrosis progression in chronic hepatitis C. Gut 54:1003-1008. https://doi.org/10.1136/gut.2004.050302

4. Sun H, Lesche R, Li DM, Liliental J, Zhang H, Gao J, Gavrilova N, Mueller B, Liu X, Wu H (1999) PTEN modulates cell cycle progression and cell survival by regulating phosphatidylinositol 3,4,5,-trisphosphate and Akt/protein kinase B signaling pathway. Proc. Natl. Acad. Sci. 96:6199-6204. https://doi.org/10.1073/pnas.96.11.6199

5. Chalhoub N, Baker SJ (2009) PTEN and the PI3-kinase pathway in cancer. Annu Rev Pathol 4:127-150. https://doi.org/10.1146/annurev.pathol.4.110807.092311

6. Dahia PL (2000) PTEN, a unique tumor suppressor gene. Endocr Relat Cancer 7:115-129. https://doi.org/10.1677/erc.0.0070115

7. Kang-Park S, Lee YI, Lee YI (2003) PTEN modulates insulin-like growth factor II (IGF-II)-mediated signaling; the protein phosphatase activity of PTEN downregulates IGF-II expression in hepatoma cells. FEBS Lett 545:203-208. https://doi.org/https://doi.org/10.1016/S0014-5793(03)00535-0

8. Di Cristofano A, Pesce B, Cordon-Cardo C, Pandolfi PP (1998) Pten is essential for embryonic development and tumour suppression. Nat Genet 19:348-355. https://doi.org/10.1038/1235

9. Milella M, Falcone I, Conciatori F, Cesta Incani U, Del Curatolo A, Inzerilli N, Nuzzo CMA, Vaccaro V, Vari S, Cognetti F, Ciuffreda L (2005) PTEN: Multiple Functions in Human Malignant Tumors. Front Oncol 5:24. https://doi.org/10.3389/fonc.2015.00024

10. Cho J, Baek W, Yang S, Chang J, Sung YC, Suh M (2001) HCV core protein modulates Rb pathway through pRb downregulation and E2F-1 up-regulation. Biochim Biophys Acta 1538:59-66. https://doi.org/10.1016/s0167-4889(00)00137-3

11. Zhang Y, Li RQ, Feng XD, Zhang YH, Wang L (2014) Down-regulation of PTEN by HCV core protein through activating nuclear factor-Kb. Int J Clin Exp Pathol 7:7351-7359. https://pubmed.ncbi.nlm.nih.gov/25550771

12. Anzola M (2004) Hepatocellular carcinoma: role of hepatitis B and hepatitis C viruses proteins in hepatocarcinogenesis. J Viral Hepat 11:383-393. https://doi.org/10.1111/j.1365-2893.2004.00521.x

13. Chung T, Lee Y, Kim C (2004) Hepatitis B viral HBx induces matrix metalloproteinase-9 gene expression through activation of ERKs and PI-3K/AKT pathways: Involvement of invasive potential. FASEB J 18:1123-1125. https://doi.org/10.1096/fj.031429fje

14. Weng LP, Smith WM, Brown JL, Eng C (2001) PTEN inhibits insulin-stimulated MEK/MAPK activation and cell growth by blocking IRS-1 phosphorylation and IRS-1/Grb-2/Sos complex formation in a breast cancer model. Hum Mol Genet 10:605616. https://doi.org/10.1093/hmg/10.6.605

15. Baig MH, Ahmad K, Rabbani G, Danishuddin M, Choi I (2018) Computer Aided Drug Design and its Application to the Development of Potential Drugs for Neurodegenerative Disorders. Curr Neuropharmacol 16:740-748.

https://doi.org/10.2174/1570159X15666171016163510

Page $16 / 22$ 
16. Harvey AL (2008) Natural products in drug discovery. Drug Discov Today 13:894-901. https://doi.org/10.1016/j.drudis.2008.07.004

17. Ntie-Kang F, Nwodo JN, Ibezim A, Simoben CV, Karaman B, Ngwa VF, Sippl W, Adikwu MU, Mbaze LM (2014) Molecular modeling of potential anticancer agents from African medicinal plants. J Chem Inf Model 54:2433-2450. https://doi.org/10.1021/ci5003697

18. Al-snafi AE (2017), The medical importance of Cydonia oblonga-A review. IOSR. J. Pharm. 6 (2017) 87-99

19. Lipinski CA, Lombardo F, Dominy BW, Feeney PJ (2001) Experimental and computational approaches to estimate solubility and permeability in drug discovery and development settings. Adv Drug Deliv Rev 46:3-26. https://doi.org/10.1016/s0169409x(00)00129-0

20. Morris GM, Goodsell DS, Halliday RS, Huey R, Hart WE, Belew RK, Olson AJ (1998) Automated docking using a Lamarckian genetic algorithm and an empirical binding free energy function. J Comput Chem 19:1639-1662. https://dasher.wustl.edu/chem430/readings/jcc-19-1639-98.pdf

21. Morris GM, Huey R, Lindstrom W, Sanner MF, Belew RK, Goodsell DS, Olson AJ (2009) AutoDock4 and AutoDockTools4: Automated docking with selective receptor flexibility. J Comput Chem 30:2785-2791. https://doi.org/10.1002/jcc.21256

22. Abraham MJ, Murtola T, Schulz R, Páll S, Smith JC, Hess B, Lindah E (2015) Gromacs: High performance molecular simulations through multi-level parallelism from laptops to supercomputers. SoftwareX 1-2:19-25. https://doi.org/10.1016/j.softx.2015.06.001

23. Zoete V, Cuendet MA, Grosdidier A, Michielin O (2011) SwissParam: a fast force field generation tool for small organic molecules. J Comput Chem 32:2359-2368. https://doi.org/10.1002/jcc.21816

24. Price DJ (004) A modified TIP3P water potential for simulation with Ewald summation. J. Chem. Phys. 121:10096-10103. https://doi.org/10.1063/1.1808117

25. Glättli A, Daura X, Van Gunsteren WF (2002) Derivation of an improved simple point charge model for liquid water: SPC/A and SPC/L. J Chem Phys 116:9811-9828. https://doi.org/10.1063/1.1476316

26. Darden T, York D, Pedersen L (1993) Particle mesh Ewald: An $N \cdot \log (\mathrm{N})$ method for Ewald sums in large systems. J Chem Phys 98:10089-10092. https://doi.org/10.1063/1.464397

27. Hess B, Bekker H, Berendsen HJC, Fraaije JGEM (1997) LINCS: A Linear Constraint Solver for molecular simulations. J. Comput. Chem. 18:1463-1472. https://doi.org/10.1002/(SICI)1096-987X(199709)18:12<1463::AID-JCC4>3.0.C0;2-H.

28. Bussi G, Donadio D, Parrinello M (2007) Canonical sampling through velocity rescaling. J Chem Phys 126(1):014101. https://doi.org/10.1063/1.2408420

29. Parrinello M, Rahman A (1981) Polymorphic transitions in single crystals: A new molecular dynamics method. J Appl Phys 52:7182-7190. https://doi.org/10.1063/1.328693

30. Liu YZ, Wang XL, Wang XY, Yu RL, Liu DQ, Kang CM (2016) De novo design of VEGFR-2 tyrosine kinase inhibitors based on a linked-fragment approach. J Mol Model 22(9):222. https://doi.org/10.1007/s00894-016-3088-8

31. Khan T, Dixit S, Ahmad R, Raza S, Azad I, Joshi S, Khan AR (2017) Molecular docking, PASS analysis, bioactivity score prediction, synthesis, characterization and biological activity evaluation of a functionalized 2-butanone thiosemicarbazone ligand and its complexes. J Chem Biol 10:91-104. https://doi.org/10.1007/s12154-017-0167-y

32. Barford D, Flint AJ, Tonks NK (1994) Crystal structure of human protein tyrosine phosphatase 1B. Science 263:1397-1404

33. Stuckey JA, Schubert HL, Fauman EB, Zhang ZY, Dixon JE, Saper MA (1994) Crystal structure of Yersinia protein tyrosine phosphatase at $2.5 \AA$ and the complex with tungstate. Nature 370:571-575. https://doi.org/10.1038/370571a0

34. Jia Z, Barford D, Flint AJ, Tonks NK (1995) Structural basis for phosphotyrosine peptide recognition by protein tyrosine phosphatase 1B. Science 268:1754-1758. https://doi.org/10.1126/science.7540771

35. Khan P, Parkash A, Islam A, Ahmad F, Hassan MI (2016) Molecular basis of the structural stability of hemochromatosis factor $\mathrm{E}$ : A combined molecular dynamic simulation and GdmCl-induced denaturation study. Biopolymers 105:133-142. https://doi.org/10.1002/bip.22760

36. Ali SA, Hassan MI, Islam A, Ahmad F (2014) A review of methods available to estimate solvent-accessible surface areas of soluble proteins in the folded and unfolded states. Curr Protein Pept Sci 15:456-476.

Page $17 / 22$ 
https://doi.org/10.2174/1389203715666140327114232

37. Hubbard EE, Haider MK (2010) Hydrogen bonds in proteins: role and strength. ELS. (2010)

38. Anantharaju PG, Gowda PC, Vimalambike MG, Madhunapantula SV (2016) An overview on the role of dietary phenolics for the treatment of cancers. Nutr J 15:99. https://doi.org/10.1186/s12937-016-0217-2

39. Björnsson ES (2016) Hepatotoxicity by drugs: The most common implicated agents. Int J Mol Sci 17(2):224. https://doi.org/10.3390/ijms17020224

40. Liu M, Jiang L, Guan XY (2014) The genetic and epigenetic alterations in human hepatocellular carcinoma: a recent update. Protein Cell 5:673-691. https://doi.org/10.1007/s13238-014-0065-9

41. Lin HK, Chen Z, Wang G, Nardella C, Lee SW, Chan CH, Yang WL, Wang J, Egia A, Nakayama KI, Cordon-Cardo C, TeruyaFeldstein J, Pandolfi PP (2010) Skp2 targeting suppresses tumorigenesis by Arf-p53-independent cellular senescence. Nature 464:374-379. https://doi.org/10.1038/nature08815

42. Wan X, Wang M, Jiang M, He Y, Liu S, Cao H, Qiu X, Tang L, Wu M (2003) PTEN expression and its significance in human primary hepatocellular carcinoma. Zhonghua Gan Zang Bing Za Zhi 11:490-492

43. Fu S, rong Zhou R, Li N, Huang Y, Fan XG (20160 Hepatitis B virus X protein in liver tumor microenvironment. Tumor Biol. 37:15371-15381. https://doi.org/10.1007/s13277-016-5406-2

44. Chung TW, Lee YC, Ko JH, Kim CH (2003) Hepatitis B Virus X protein modulates the expression of PTEN by inhibiting the function of p53, a transcriptional activator in liver cells. Cancer Res 63:3453-3458

45. Ishihara M, Tsuneya T, Shiota H, Shiga M, Nakatsu K (1986) Identification of new constituents of quince fruit flavor (Cydonia oblonga Mill. $=$ C. vulgaris Pers.). $\mathrm{J}$ Org Chem 51:491-495. https://doi.org/10.1021/jo00354a016

46. Adiban H, Shirazi FH, Gholami S, Kamalinejad M, Hosseini SH, Noubarani M, Eskandari MR (2019) Chemopreventive effect of quince (Cydonia oblonga Mill.) fruit extract on hepatocellular carcinoma induced by diethylnitrosamine in rats. Int Pharm Acta 2:2e2-2e1

47. Silva B, Valentão P, Seabra RM, Andrade P (2008) Quince (Cydonia oblonga Miller): An interesting dietary source of bioactive compounds. Food Chem. Res. Dev. 243-266

48. Vitaglione P, Fogliano V, Pellegrini N (2012) Coffee, colon function and colorectal cancer. Food Funct 3:916-922. https://doi.org/10.1039/c2fo30037k

49. Costa R, Magalhães A, Pereira J, Andrade P, Valentão P, Carvalho M, Silva B (2009) Evaluation of free radical-scavenging and antihemolytic activities of quince (Cydonia oblonga) leaf: A comparative study with green tea (Camellia sinensis), Food Chem. Toxicol 47:860-865. https://doi.org/10.1016/j.fct.2009.01.019

50. Pacifico S, Gallicchio M, Fiorentino A, Fischer A, Meyer U, Stintzing FC (2012) Antioxidant properties and cytotoxic effects on human cancer cell lines of aqueous fermented and lipophilic quince (Cydonia oblonga Mill.) preparations. Food Chem Toxicol 50:4130-4135. https://doi.org/10.1016/j.fct.2012.07.061

51. Yan Y, Liu N, Hou N, Dong L, Li J (2017) Chlorogenic acid inhibits hepatocellular carcinoma in vitro and in vivo. J Nutr Biochem 46:68-73. https://doi.org/10.1016/j.jnutbio.2017.04.007

52. Hill AD, Reilly PJ (2015) Scoring functions for AutoDock. Methods Mol Biol 1273:467-474. https://doi.org/10.1007/978-14939-2343-4_27

53. Sen S, Chakraborty R (2017) Revival, modernization and integration of Indian traditional herbal medicine in clinical practice: Importance, challenges and future. J Tradit Complement Med 7:234-244. https://doi.org/10.1016/j.jtcme.2016.05.006

54. Saif MW, Li J, Lamb L, Kaley K, Elligers K, Jiang Z, Bussom S, Liu SH, Cheng YC (2014) First-in-human phase II trial of the botanical formulation PHY906 with capecitabine as second-line therapy in patients with advanced pancreatic cancer. Cancer Chemother Pharmacol 73:373-380. https://doi.org/10.1007/s00280-013-2359-7

\section{Figures}




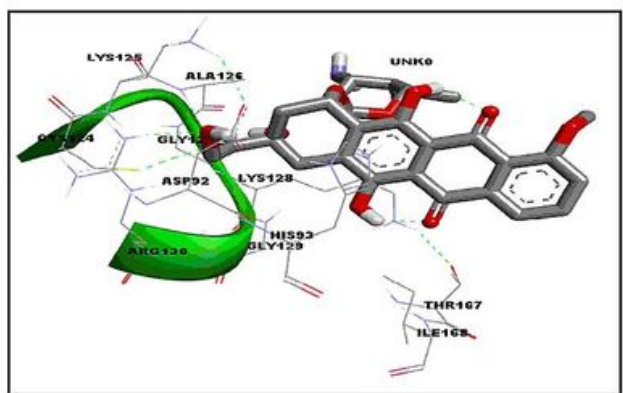

pTEN_Doxorubicin

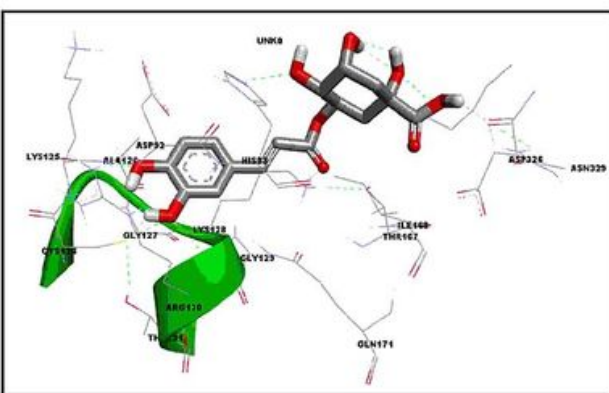

pTEN_3-O-Caffeoylquinic Acid

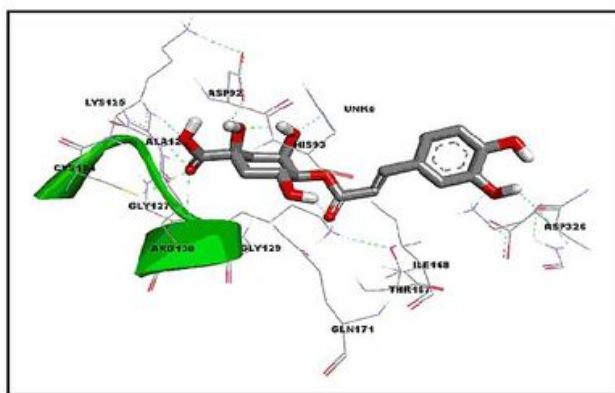

pTEN_4-O-Caffeoylquinic Acid

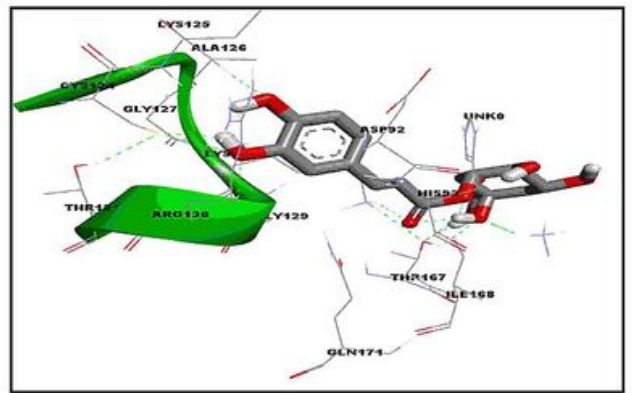

pTEN_5-O-Caffeoylquinic Acid

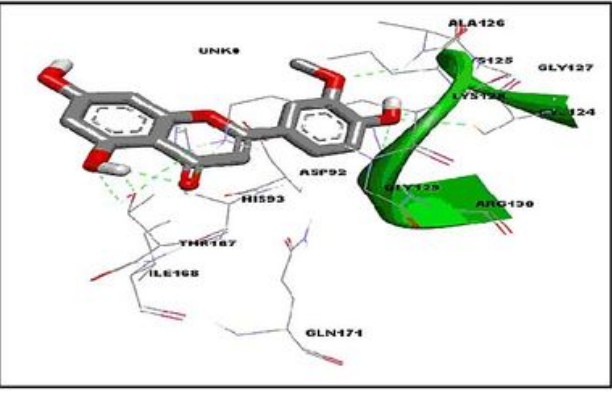

pTEN_Chrysoeriol

Figure 1

The best docked complex structure of ligands with pTEN tumor suppressor gene

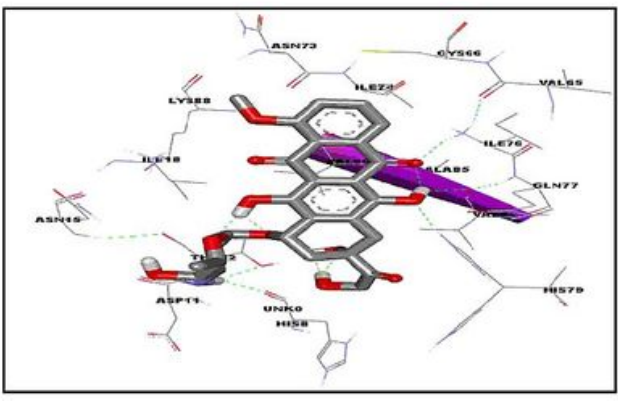

HBx_Doxorubicin

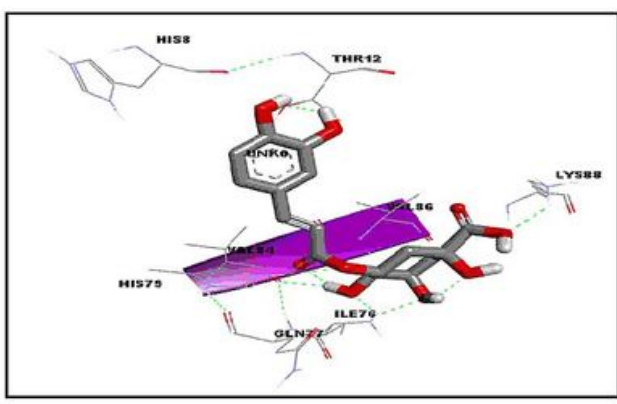

HBx_3-O-Caffeoylquinic Acid

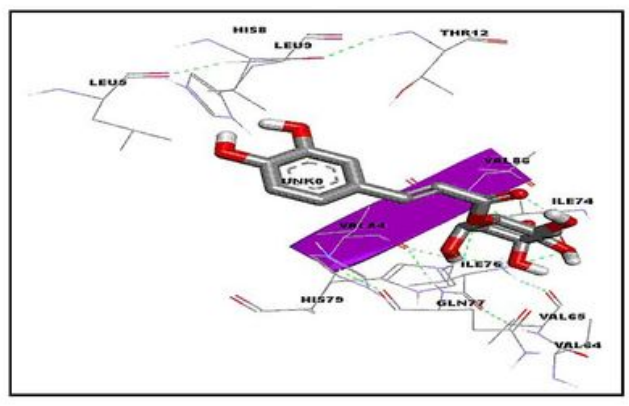

HBx_4-O-Caffeoylquinic Acid

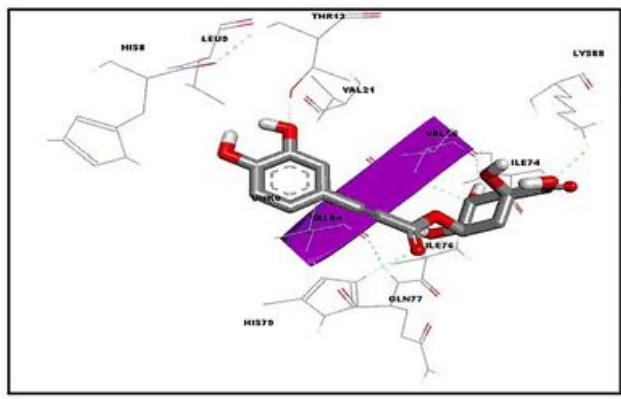

HBx_5-O-Caffeoylquinic Acid

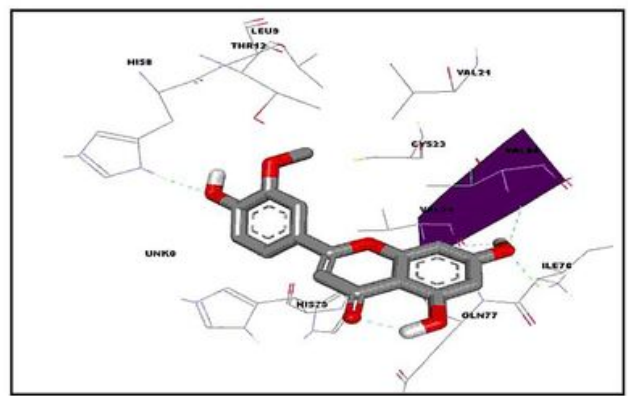

HBx_Chrysoeriol

Figure 2 


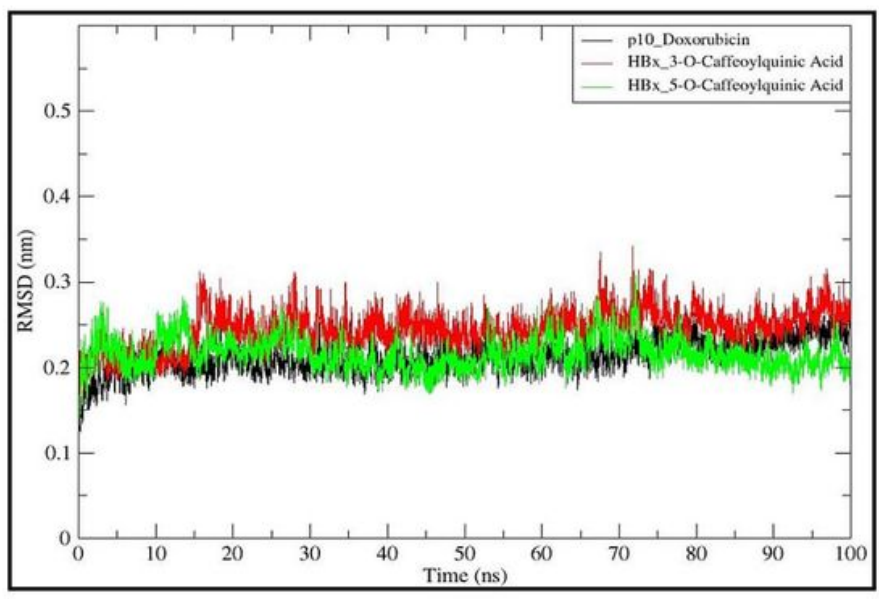

(a)

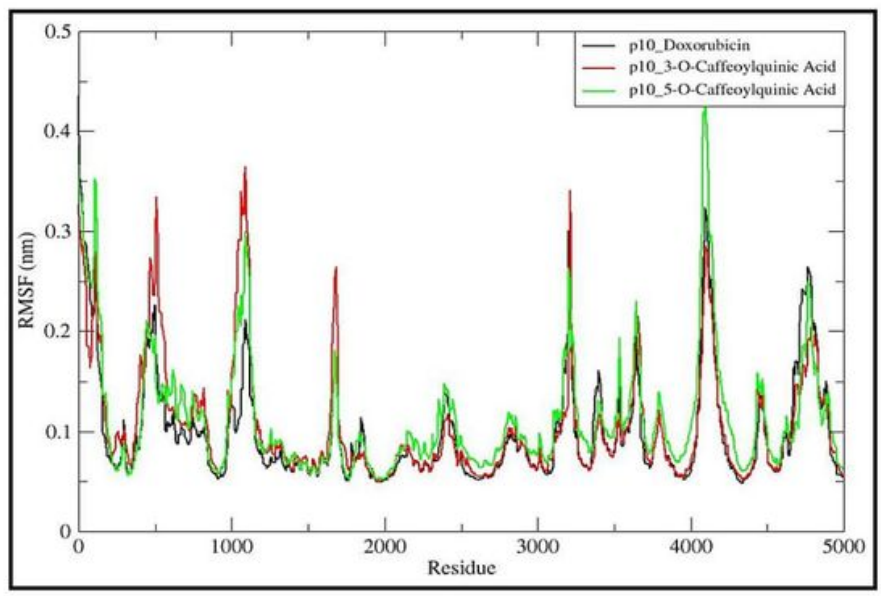

(c)

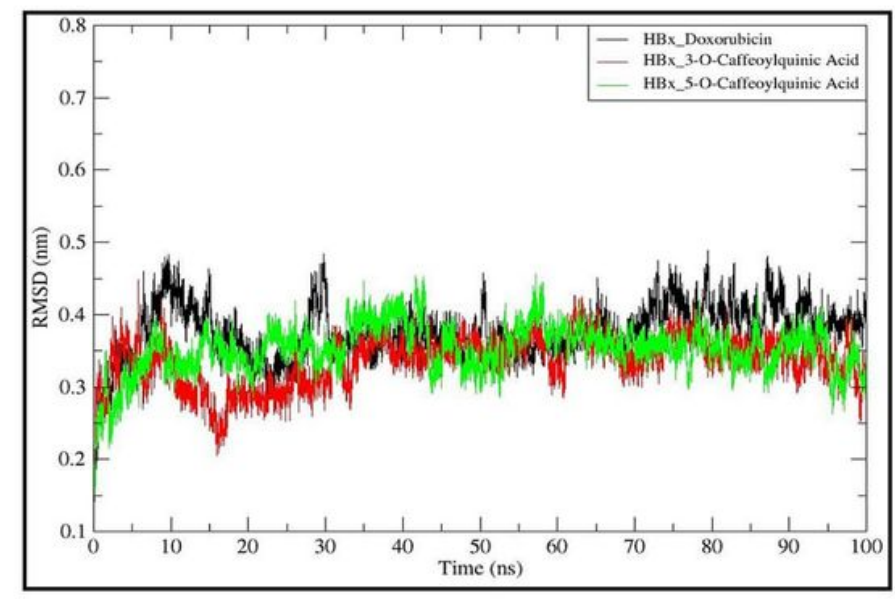

(b)

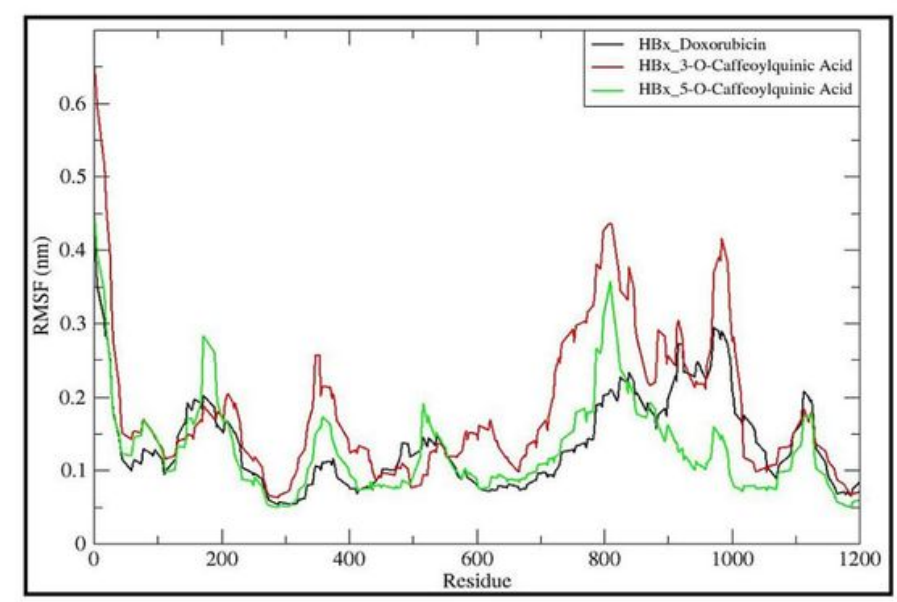

(d)

Figure 3

(a) \& (b) is the RMSD change of in PTEN and HBx backbone atoms in MD simulation, respectively; (c) \& (d) are the RMSF plot area of pTEN and HBx, respectively, with Dox(black), 3CQA (red) and 5CQA (green). 


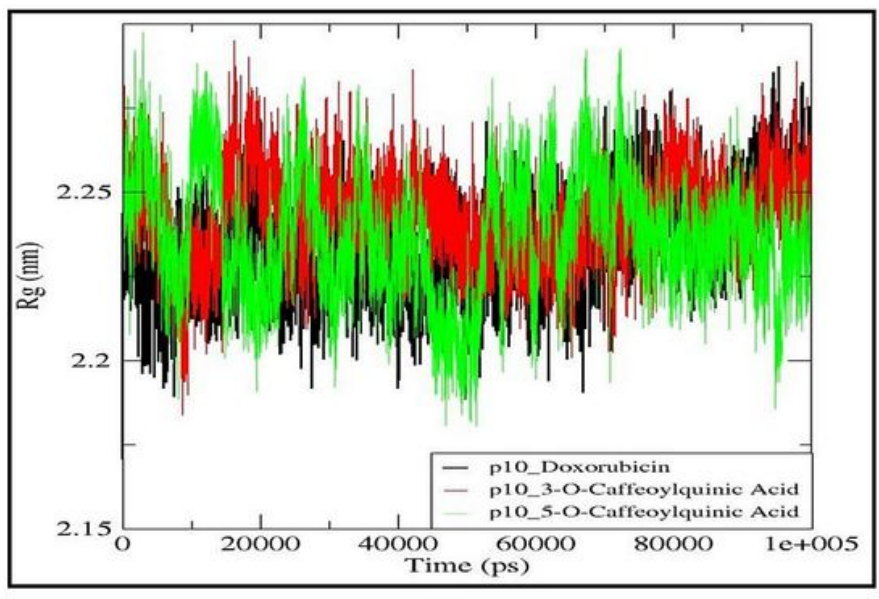

(a)

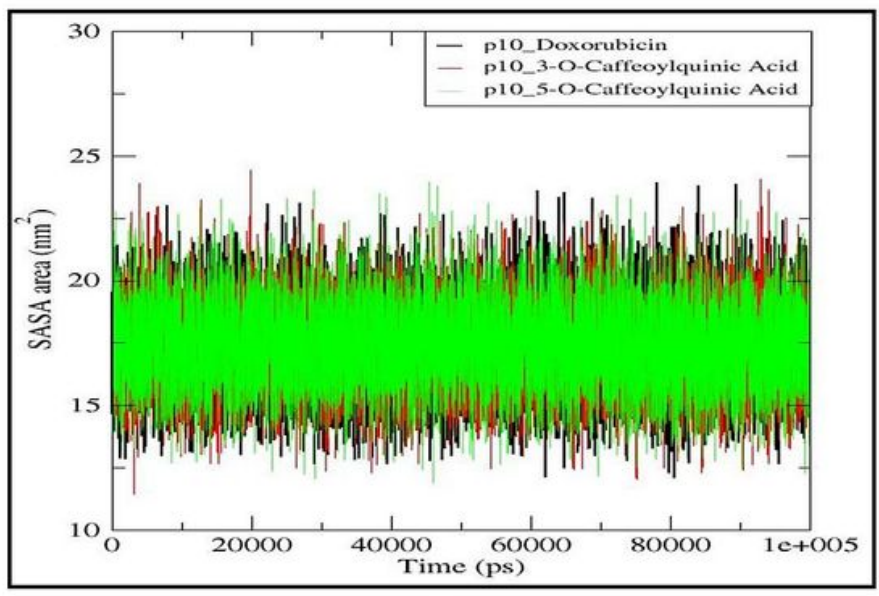

(c)

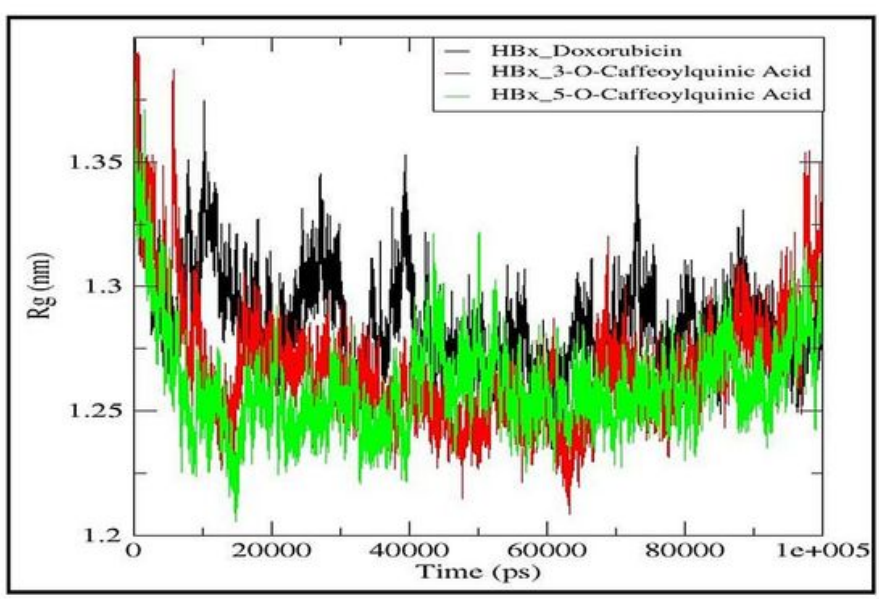

(b)

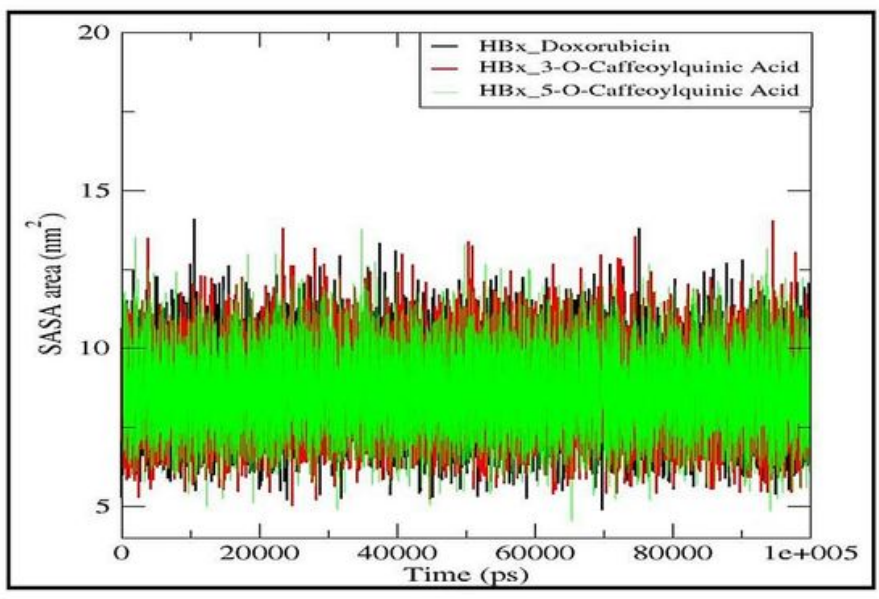

(d)

\section{Figure 4}

(a) \& (b) is the Radius of gyration ( $\mathrm{Rg}$ ) of pTEN and HBx protein in MD simulation, respectively; (c) \& (d) is the SASA plot of pTEN and HBx, respectively, with Dox(black), 3CQA (red) and 5CQA (green). 


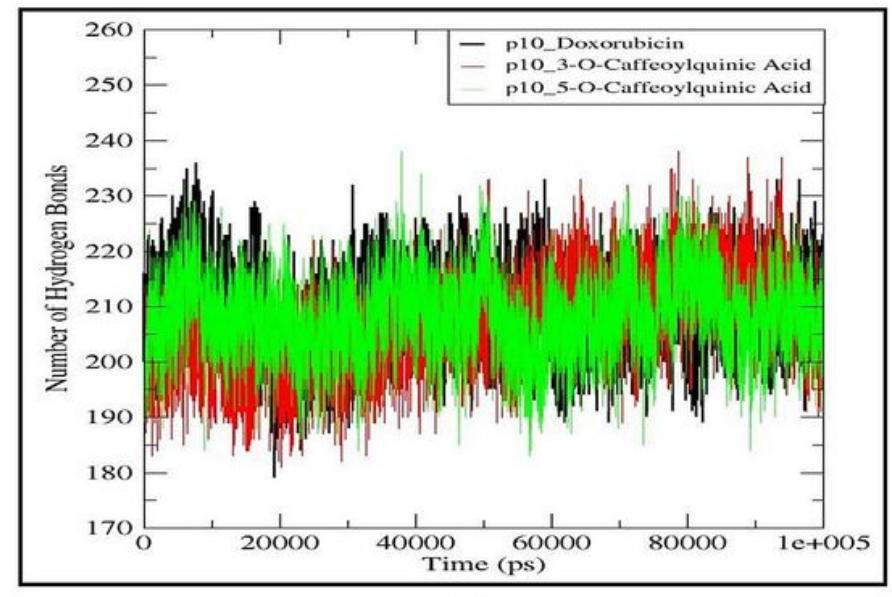

(a)

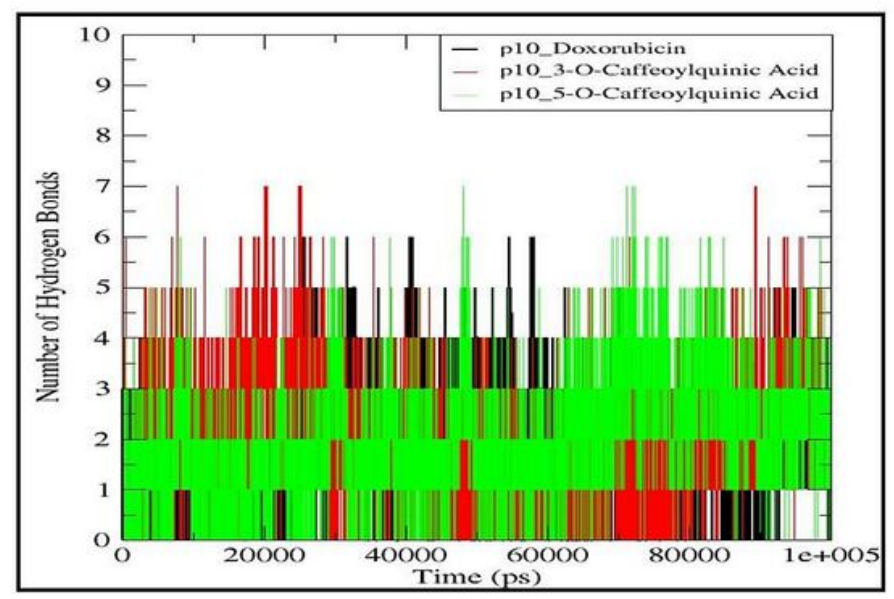

(c)

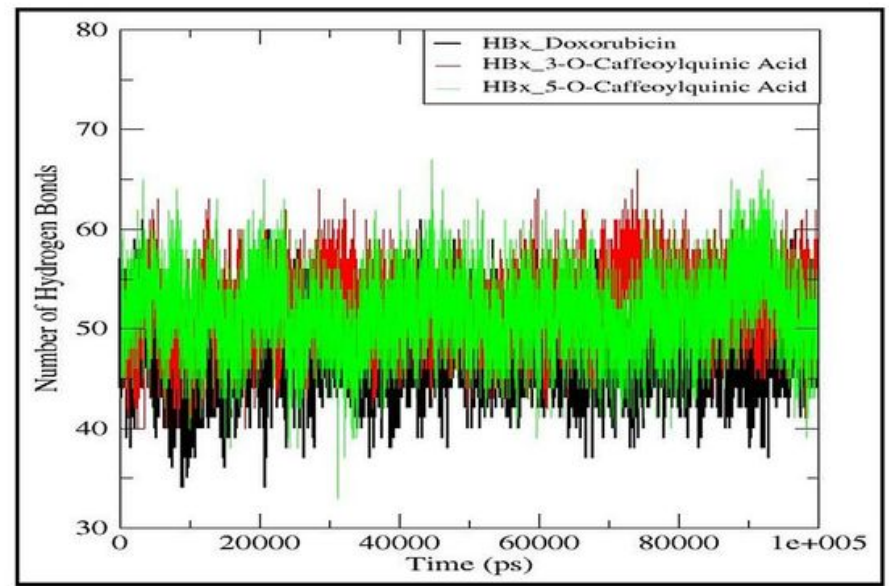

(b)

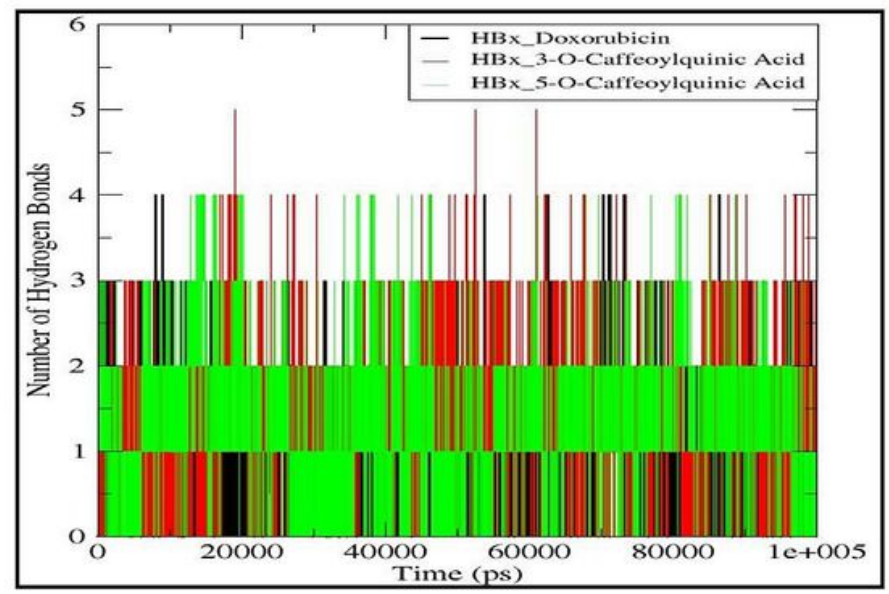

(d)

\section{Figure 5}

(a) \& (c) represents the Intramolecular Hydrogen bonds formed within PTEN and HBx protein in MD simulation, respectively; (b) \&

(d) shows the Intermolecular Hydrogen bonds between ligands (Doxorubicin, 3CQA and 5CQA, respectively) and protein targets pTEN and HBx, respectively, with Dox(black), 3CQA (red) and 5CQA (green).

\section{Supplementary Files}

This is a list of supplementary files associated with this preprint. Click to download.

- Graphicalabstract.jpg 